\title{
Research and Practice of Postgraduate Cultivation on the basis of Material Processing Characteristic
}

\author{
Hong-mei Zhang ${ }^{1, \mathrm{a}}$, Sheng-li Li ${ }^{1, \mathrm{~b}}$, Hong-yang Zhao ${ }^{1, \mathrm{c}}$, Ying-yi Liu ${ }^{1, \mathrm{~d},}, \mathrm{He}-\mathrm{ran} \mathrm{Li}^{1, \mathrm{e}}$ \\ 1.University of Science and Technology Liaoning, Anshan, Liaoning, China. \\ a.1ilyzhm68@163.com. \\ e.15938489@qq.com
}

\begin{abstract}
The construction process of cultivation model and curriculum system of materials engineering master degree candidate in university of science and technology Liaoning are introduced in this paper. The exploration and practice of different aspects such as curriculum system, cultivating model, training plan revision and contents integration and so on are discussed in this research.
\end{abstract}

Keywords-cultivation model; curriculum system; training plan;assessment of thesis

\section{INTRODUCTION}

In recent 40 years, major countries which whether developed or developing in the world will accelerate development of higher education as a strategic point for national development and the competition level of talent cultivation was upgraded significantly, developed countries all have taken the postgraduate education as the core position of national innovation development strategic, which can increase investment and speed up the pace of training. The work conference on national postgraduate education was held by the Ministry of Education, the National Development and Reform Commission and the Ministry of Finance jointly in Beijing in July 10,2013 , which opens the prelude to comprehensively promote the reform of postgraduate education integrated in our country[1].

At present, there are several problems in the postgraduate education, for instance, the overall quality of education is not high, the ability of independent innovation is weak, lacking of inner impetus on education and teaching, etc[3], the core of solving problems depend on insisting the characteristic development strategy and in terms of the original innovation and integration innovation should be worked hard, in addition, which is based on important subjects, strengthening discipline construction and scientific and reasonable to build a professional and diversified pattern of postgraduates training.

At the beginning of 2010 [2], materials engineering major in the school of material and metallurgy of university of science and technology Liaoning set about to carry out the work of characteristic discipline construction, training plan revision, curriculum system, practice system and contents integration due to the discipline advantages existing. The exploration and practice of master degree candidate cultivation mode and curriculum system construction have been completed preliminarily during January 2014 to September 2015.

\section{RESEARCH CONTENTS}

\section{A. Strengthen the construction of material processing discipline}

Throughout the world, many excellent universities are famous for some subjects[4]. Subject construction is the leader and is also the core competitive power of universities. relying on the key subjects is the inevitable course for most universities to form characteristics development. Original innovation, integration development and characteristic development strategy must be applied to discipline construction. Anshan Institute of iron and steel is the predecessor of university of science and technology Liaoning, which is characterized by the subjects of Steel Smelting and materials processing. Persevering in development with characteristic and innovation based on traditional subjects are the chief problems to be researched. Refining outstanding subjects and strengthen discipline construction is the priority among priorities. Postgraduate cultivation mode is defined as the sum of train objective, curriculum setting, tutor guidance, and dissertation assessment in the progress of cultivating. Training model is a dynamic development concept, its internal elements are affected by educational thought, educational theory and time development, and so different cultivation models are produced indifferent time. At present, with the rapid development of the scale of postgraduate education in our country, The need of high level specialized talents is becoming more and more diversified for enterprises.

\section{B. Determination of postgraduate training objective in material processing subject field}

The training objective is the general principle and the general direction for the cultivation of talents, it is not only the premise and foundation of the training activity, but also the destination of all the training activities. Postgraduate training objectives require to meet the need of the basic requirements and specifications of the postgraduates should have through the process of education. To be specific, training objectives demanded to reach the standard in terms of moral structure knowledge structure and quality structure. 
Postgraduates are demanded to know solid theoretical foundation and rich professional knowledge in material engineering filed well, meanwhile, modern experimental research methods and technological means of solving problems and the abilities of handling engineering technology and engineering management problems independently are required[5]. The ability to undertake scientific research or independently to engage in a special technical work, rigorous style of scientific research, nice spirit of cooperation, and strong skills of communications are also wanted for postgraduates actually.

\section{Taking the cultivation of innovation ability as orientation, constructing the modularized curriculum system}

\section{1) Training plans are revised carefully}

Education objective system is the blueprint of the quality and specifications of personnel training, and cultivation plan is the fundamental condition which can make the blueprint come true. In early 2011, university of science and technology Liaoning was based on the extensive and systemic survey work to revise the training programs of postgraduates and to arrange the courses scientifically and systematically under the condition of the train objectives were confirmed according to the requirements of the National Education Professional Degree Education Steering Committee. Cultivation plans were analysed and demonstrated systematically again in view of the first revision of the training programs on the basis of the National Education postgraduate training program was issued by the National Education Professional Degree Education Steering Committee. The effectiveness of this revision was performed excellently in two aspects, on the one hand, the course structure and the course construction were accepted highly and developed continuously respectively due to the clear course objectives, the other hand, and modular curriculum structure was achieved perfectly.

Course offered is the key link of mastering a solid theoretical foundation and a wide range of professional knowledge and possessing the abilities of scientific research and practical work. Curriculum setting reflects the connotation of knowledge structure, academic degree and professional degree postgraduates acquired to master different knowledge categories,so curriculum setting also reflects the difference.

The thought of "There is different specializing in" and the capacity of technology innovation which is corresponding to the profession are taken as the oriention to set up the relevant courses and building modular curriculum system. Five research directions which are corresponding to the industries directly are added in the curriculum system of postgraduates on basis of the existing advantages of material engineering discipline and the foundation of cooperating with companies for many years, such as the synthesis of refractory materials for metallurgy, material preparation and process design, high performance materials basic application research and new material design, Material processing technology and equipment, solidification theory and processing technology of short process, surface engineering and new energy materials and engineering.
The aim of training professional degree postgraduates is to make the postgraduates become the high-class doers and high level compound talents with solid theoretical foundation. Mastering a certain system is not the purpose of curriculum setting, curriculum setting puts professional ability first , modular system is rather favorable to these postgraduates. The modular curriculum system divides the course which set by a certain profession into several relative independent modules, and all the modules are combined into one system in a certain form. The advantages of the modular curriculum system is that it is beneficial to the synthesis of different subject curriculum, a module can be composed of several subjects, the relative independent and horizontal connection between the modules, the curriculum integration of unrelated discipline forming the comprehensive cultivation for specified professions. Modular curriculum system shows the flexibility of the curriculum setting, modules can be increased or decreased on the basis of the actual need, latest scientific and technological achievements and advanced experiences are absorbed to the modules which make the alteration of curriculum system more elastic.

The purpose of opening basic theory knowledge and professional knowledge which in modular curriculum system is to improve the theoretical level of postgraduates. The aim of setting up technology and practice section is to develop the skills of postgraduates and improve the abilities for solving practical problems. The objective of adding electives is to enhance the general qualities of postgraduate and broaden the knowledge fields. Postgraduates of professional type are required to complete engineering practice report by practicing in the factories or participating in other engineering practices. Professional postgraduates are encouraged to practice in enterprises, the way of concentrated practice and segmentation could be applied postgraduates are demanded to finish the engineering practice report which values 6 credits .Experienced professionals of enterprises are employed to introduce the latest technology and research results of engineering fields and the technical matters existent today in the courses of special topics. Postgraduates are demanded to take part in 5 academic activities at least in two years, expert lectures and academic reports are included in the academic activities, and meanwhile postgraduates are also asked to write a summary which consists of 1000 words at least.

\section{2) Teaching materials construction}

a) Educational thoughts and ideas which accord with the time features are taken as the guideline and the quality education is treated as the core[6].Teaching materials construction starts with optimizing curriculum system to make the development of knowledge, ability, and quality more harmonious and then to develop the curriculum syllabus, standardize the construction of teaching materials, and deepen the reform of teaching materials.

b) We should pay sufficient attention to the important position of teaching materials in teaching field, strengthen the management of teaching material construction and promote the work of materials construction to carry out in a deep-going way in order to make sure the successful implementation of materials construction plan. 
c) It is essential to further increase the position of education department planning materials, national key textbook and the excellent teaching materials of ministry and province in personnel training. Ascertaining the function of teaching material construction in the development of institutions of higher learning is also necessary.

d) Stirring up the enthusiasm of teachers to write teaching materials and encouraging teachers to make more good teaching materials by rewarding awarded textbooks.

3) The establishment of research institute of coalition of college and enterprise, the long term effectiveness of cooperation mechanism.

Postgraduate's tutors are encouraged to utilize the resource advantages of the cooperative projects with enterprises to arrange postgraduates who are in type of profession to practice in the relevant enterprises. Research institute of coalition of college and enterprise which established by university of science and technology liaoning and Ansteel group forming the long term effectiveness of cooperation mechanism. The cultivation mode of the cooperation between university and enterprise is applied to cultivate postgraduate and dual tutors system of tutor and senior technical personnel in the enterprises is put into practice. Postgraduates are guided and trained by the tutor in the university who has the deep theoretical foundation and strong practical work ability and the tutor in enterprise who has higher basic theory level and strong guidance ability Tutor in university and the tutor in the enterprise need to communicate regularly to make the routine work of postgraduates clear and to know the development situation of postgraduate's thesis. University administration is responsible for the management of academic degree and archives of postgraduates. During the study period in the university, the student work department and the tutor in school are responsible for the daily management of postgraduate and during the practice period in the enterprise, enterprise training department and the tutor in enterprise are responsible for the daily management of postgraduate. Dual tutors are not only responsible for the thesis work of postgraduates, but also paying attention to the safety, thought, life, employment of postgraduates to ensure the postgraduates working in the paper full fledge. The selection of thesis title should root in the enterprise production practice but the theoretical foundation of thesis should be ensured simultaneously for sake of ensuring the unification of theory and practice. Firstly, enterprises propose the thesis title according to the existing problems. Secondly, the tutor in university communicates with the tutor in enterprise repeatedly to estimate whether the title can be taken as the master's degree thesis title or not on the basis of thesis requirements of academic degree. Finally, the frame of thesis is formed and the technology secrecy agreement is signed for guaranteeing the thesis work achieved satisfactorily after the discussion of the dual tutors.

\section{THE ASSESSMENT OF SCHOLARSHIP}

\section{a) the assessment of scholarship}

The scholarship of postgraduate is assessed synthetically in the light of the academic record, the situation of practice and scientific research and the numbers of papers and patents published. The assess of scholarship is fair and equitable for postgraduates ensuring the benefits of postgraduates.

\section{b) the assessment of thesis:}

The targets of the education for professional degree postgraduates is to cultivate application type talents in high level, the purpose of writing the thesis lies in enhancing the abilities of postgraduates for solving practice problems and researching practice problems, social, economic and practical values are highlighted in the dissertation. Professional degree thesis must be based on practice, researching the problems in practice according to the investigations. Accurate data collections and rigorous demonstrations are included in the thesis; the results of the dissertation are advanced and feasible. Excellent professional degree thesis not only has the guidance and reference value, but also can bring economic benefit and social benefit to the practical department.

Graduate level and characteristics of professional degree should be embodied in the professional degree thesis, the thesis does not necessarily emphasize the pure academic research, but also can not be degraded to a simple summary of practical work, and comprehensive use of the theory and knowledge for solving practical problems of authors should be reflected in postgraduate thesis. The thesis not only pays attention to the theoretical knowledge but also pays great attention to the use of theoretical knowledge, so the comprehensiveness of application value and academic value are treated as the assessment criterion of professional degree thesis.

The dissertation proposal conference of master' $\mathrm{s}$ degree is organized uniformity by discipline master points. Literature review, experimental plan and the scheduled plan of thesis are checked in the process of dissertation proposal conference. The research situation of postgraduates on the topic, the situation of collection and analysis of relevant information, the situation of collection of experimental data and experimental results and the problems and solutions existing are checked by tutors. Graduation Defense Committee consists of related personnel inside and outside school, the achievement of degree thesis comprises the score of three parts of tutor, reviewer and the committee of defense.

\section{LOOK INTO THE DISTANCE}

A practical cultivation plan for postgraduates has been groped gradually on the basis of the experience accumulated by us. The constructions of cultivation model for teaching, practice and thesis are improved step by step. Training of postgraduates is gradually moving towards the right track, the subject, enterprise and students has formed the win-win situation. In the discipline, we not only meet the needs of the society for postgraduates but especially in the process of postgraduates cultivated by the combination of enterprises and universities, scientific research ability is shown to the enterprises and accepted by them. The ideas ,exploration and the practice of postgraduates also needed to further refined .we should constitute the postgraduate cultivation scheme and the education plan which could not only possess the Chinese characteristics, but also accord with the development tendency of the world[7]. 
The improvement of the quality of postgraduate training depends on the sense of responsibility and dedication of every tutor. Tutors should reflect on their own teaching ideas, knowledge structure, teaching process and methods, and the relationship with postgraduates, and adjust their teaching ways constantly to meet the needs of the rapid development of society.

We will continue to absorb the advanced experience at home and abroad for developing work pertinently with the social needs to make the cultivation of postgraduates more effective.

\section{REFERENCES}

[1] Ning Yang, "research on the cultivation of professional degree postgraduates" Da Lian:DA LIAN University of technology,2010;21-22.

[2] HU Song qing ,ZHANG Jun,GUO Wen yue.improvement of cultivating quality of science and engineering and full-time professional degree postgraduates[J].Aug.2011

[3] $\mathrm{Hu}$ Lin ling,the distinction of professional degree postgraduates and academic degree postgraduates[J].postgraduate teaching.2006(4)

[4] Liu Yue nan,the problems and solution existing in Chinese universities.NanJing Tech university,2014.

[5] Liu Yan dong,promoting quality for ensuring the continuous development of postgraduates teaching[EB/OL].2011-10-14.

[6] Yuan Ben tao,Yan Jian lin.The analysis on the present situation of postgraduate's innovation ability and the influencing factor.[J].Peking University education review.2009(2):12-20.

[7] Aiguo Wang.enhancing the schooling level of the special higher education and perfecting the disabled people higher education system.international education studies.2009.Vol.2(2). 